\title{
Application of Water Quality of pH and TSS Monitoring Using Online Monitoring at Settling Pond of Coal Mining Company PT XY
}

\author{
Putih Fajariyadi \\ Student Master of Business Administration in Lambung Mangkurat University, South Kalimantan, Indonesia
}

\begin{abstract}
The existence of an Online Monitoring System is very important to know in real time the changes in water quality at Settling Pond so that it can immediately take action to maintain the quality of water from the settling pond always comply with the required environmental quality standards without errors resulting in mine closure and criminal sanctions. To face this challenge, a system needs to be developed that can monitor real time output water settling ponds, so that early warning can be provided if the settling pond requires special handling, to the team in charge. Currently water quality monitoring is still done manually, namely by doing water sampling and quality testing manually. This stage uses at least 12 teams to supervise 18 active, controlled settling ponds 24 hours and 7 days a week. In the implementation there were quite a number of challenges faced, apart from the fact that the Settling Pond location was quite far away so that it took quite a long time to reach the location. The applicable laws and regulations state that mine water management must not exceed the required environmental quality standard (BML) so that fast information is needed to be able to know water quality.
\end{abstract}

Keywords: Online Monitoring System, Water Quality

DOI: $10.7176 / \mathrm{JIEA} / 11-2-03$

Publication date: April $30^{\text {th }} 2021$

\section{Introduction}

The world of mining is synonymous with efforts to utilize natural resources with impacts that can disrupt the balance of the environment. Mining business produces mine water that must be managed so that it matches the Environmental Quality Standards (BML) before being released into public waters (creeks / rivers).

PT. XY in Kalimantan manages annual water of around 400 million $\mathrm{m} 3$ both from rainwater through the catchment area and from the mine pit. Mine water management conducted by PT. One of them is by building Settling Pond. The sedimentation system in Settling Pond is assisted by chemicals to separate dissolved solids with water and to increase the $\mathrm{pH}$ of the water.

Flowchart of Mining Process \& Environmental Management:।

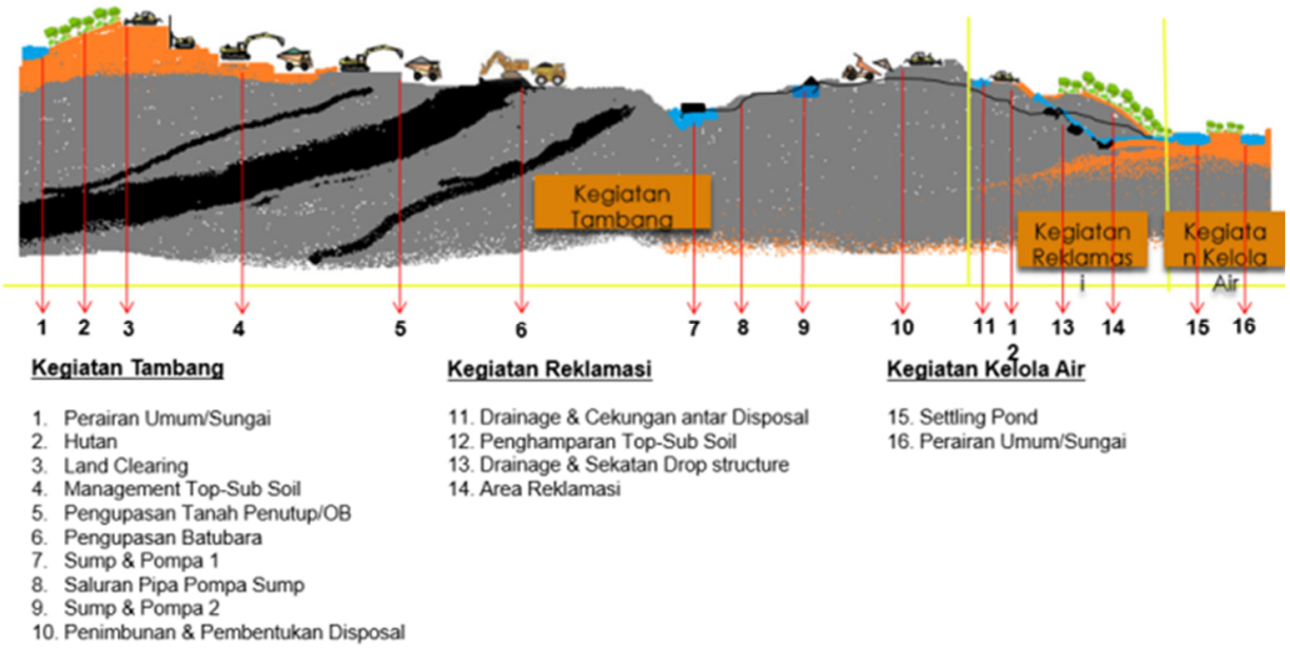

The government, in this case starting at the ministerial level, the governor, and the regent, regulates the implementation of environmental management, especially mine water management.

\section{Stages of Mine Water Management:}

- Analyze environmental impacts during mining activities. In this case the management of surface water from the disturbed area into Settling Pond.

- Making Settling Pond design by considering the area of catchment area (catchment area) and rainfall.

- Making settling pond (settling pond)

- Mine water treatment also considers the amount of water discharge, rainfall and characteristics of mine 
water to be processed.

- Treatment of Swimming Pools due to sedimentation.

- $\quad$ Monitoring of output water at compliance points according to established monitoring parameters ( $\mathrm{pH}$ and TSS).

\section{Water Quality Monitoring}

At present the monitoring of water quality on the settling pond is done conventionally by taking water samples and then testing the quality in the laboratory. This method has weaknesses, namely less practical, requires competent human resources and a high factor of human error. In addition, because the location of the remote settling pond takes more time to get to the monitoring location. This conventional method also does not have the ability to collect good data to be used again to find out the water quality characteristics in the location as a predictor of future water quality.

\section{Remote Monitoring System (Monitoring Online)}

To overcome the above problems, a water quality monitoring system is needed in real time and continuously to be applied at Settling Pond compliance points. If monitoring can be carried out continuously, a data baseline will be obtained. Data baseline is very necessary to analyze the problems that occur, and evaluate the success of the efforts that have been made in relation to the control of water management that has been carried out. This system can collect all water quality monitoring data and can provide early warning if the water quality is close to the prescribed limit of Environmental Quality Standards. Early warning can be sent automatically to registered telephone numbers in the system.

Definition:

Settling Pond (SP): a water drainage system in the form of a pond that functions as a sedimentation pond for all water from a mining area, both groundwater and rainwater which aims to purify the water coming out into public waters in accordance with the stipulated Environmental Quality Standards.

Total Suspended Solid (TSS): dry weight of suspended particles, which are not dissolved in water samples that can be trapped by filters that are analyzed using a filtration device. These are water quality parameters used to assess the quality of all types of water or water bodies, for example seawater or waste water after treatment at a wastewater treatment plant.

$\mathrm{pH}$ : a logarithmic scale used to determine the acidity or basicity of an aqueous solution.

Monitoring Online: Online: English, in Indonesian is online (while Offline = offline) has certain meanings in terms of computer technology and telecommunications. In general, "online" indicates a connected state, while "offline" indicates a disconnected state. Online can also be interpreted as a state of the computer that can exchange information because it is connected. So online monitoring is a form of integrated and interconnected (with computer) monitoring.

Telemetry: Is a method of measuring an object that can be done remotely. By placing a sensor or transducer on the object being measured, the measurement data can be taken remotely by using various data communication methods and various media for communication.

Data (satellite, radi frequency, etc.). In this research activity uses a GSM network as a medium for data communication, while the methods used are SMS and data calls.

\section{Research Methods}

The main objective of this research activity is the realization of a model of the Water Quality Monitoring System from the settling pond that can work online, and is capable of continuous and real time monitoring. The target of the activity included the construction of a water quality monitoring station model and a data collection station / master station.

It is hoped that this monitoring system will be in accordance with the monitoring needs of Settling Pond (SP) at PT XY. The methodology used in this activity is to take the case in SP O. That is by looking at the conditions of the compliance point on SP O then designing the building and online water quality monitoring system.

The online water quality monitoring design is described as follows: 

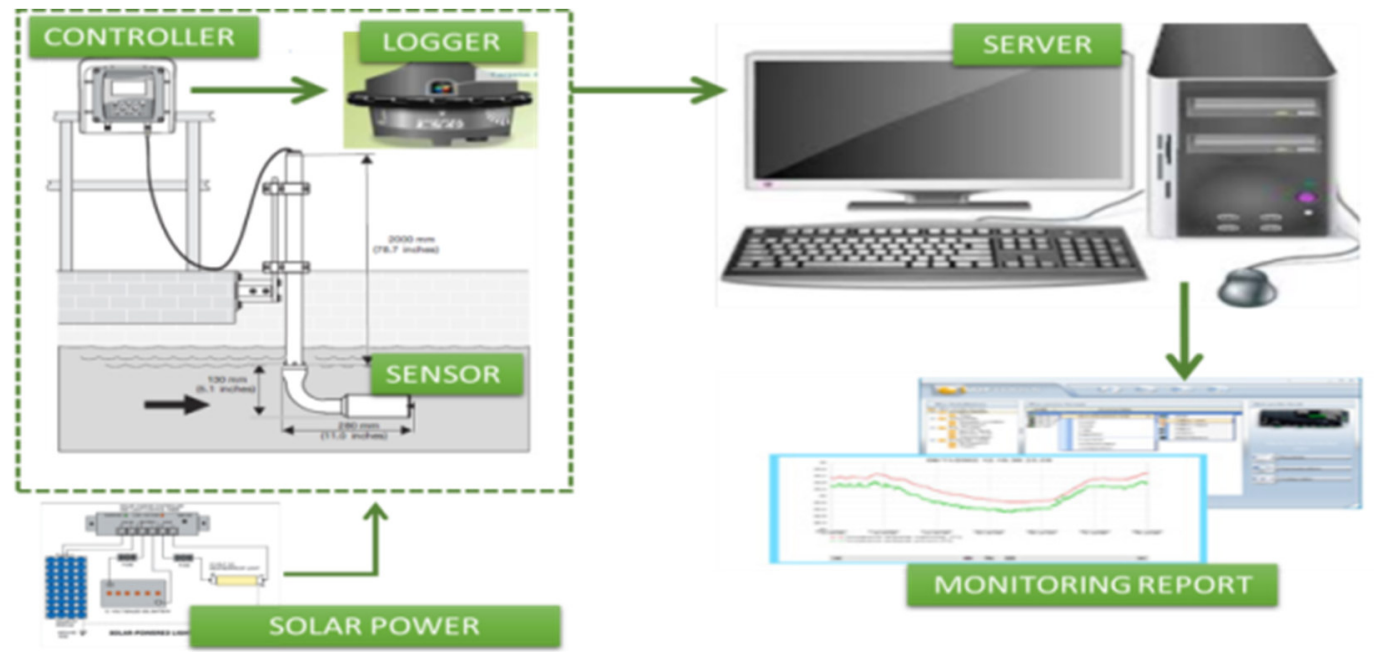

Figure 1. Online Monitoring System Design

At the Settling Pond compliance point, the operation center of this system will be placed which consists of: data logger center, controller and sensor ( $\mathrm{pH}$ and TSS). Data logger functions to store and send data that is read by sensors to the server. The controller functions to read and display sensor reading data.

Then the data will be sent to the server in the office and displays the results of monitoring online in the dashboard on the monitor screen. This system is also designed to send an early warning system if the water quality reading sensor is close to the environmental quality threshold to telephone numbers that have been registered in the system. The early warning system was sent in the form of an SMS notification that provides information on the quality of $\mathrm{pH}$ and TSS of water.

\section{Discussion \& Result}

The online water quality monitoring system designed is with components using:

1. HACH sc 200 Controller

This controller has advantages such as ease of data transfer because there is a slot for MicroSD, it can be connected directly to the sensor easily, has a screen display on the controller so that we can know directly whether the sensor is working, a wide combination of sensors that have never been in series previous series.

2. $\mathrm{HACH} \mathrm{pH}$ Sensor

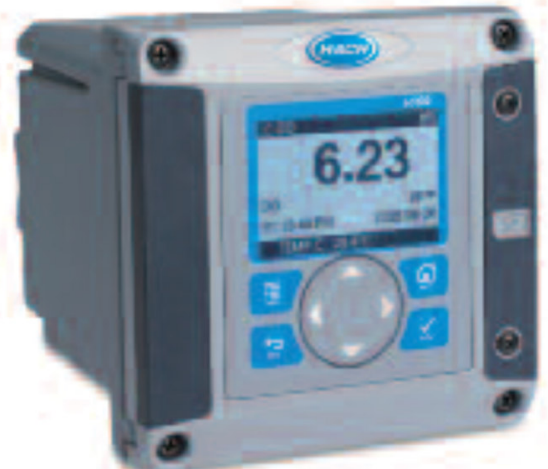

Figure 2. HACH sc 200 Controller

Compatible with the HACH sc 200 Controller. Most pH applications in the $\mathrm{pH}$ range 2.5 to 12.5 . Hach $\mathrm{pHD}$ sc The $\mathrm{pH}$ differential sensor with a glass wide electrode process works very well in this range. Some industrial applications require accurate measurements and controls under 2 or above $12 \mathrm{pH}$. In addition, the sensor cable that reaches a length of up to 10 meters is very suitable for use in the planned location of this system placement. 


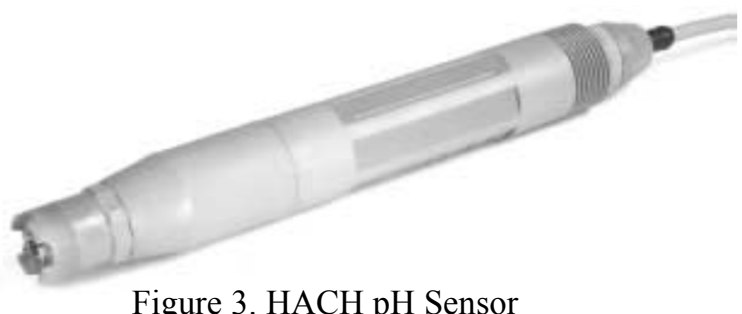

3. Solitax sc Suspended Solid Sensor

Figure 3. HACH pH Sensor

Compatible with the HACH sc 200 Controller. Sensors are immune to discoloration that is affected by deposits caused by variations in flow volume, climate fluctuations, or other unexpected events. Unlike conventional systems, which need to be continuously calibrated to compensate for color variations, measurement techniques used on the sc sensor SOLITAX is the only technology that provides full measurement independent of color. Online measurement not only saves time on manual analysis but also delivers in real time TSS measurements so that operations are more efficient.

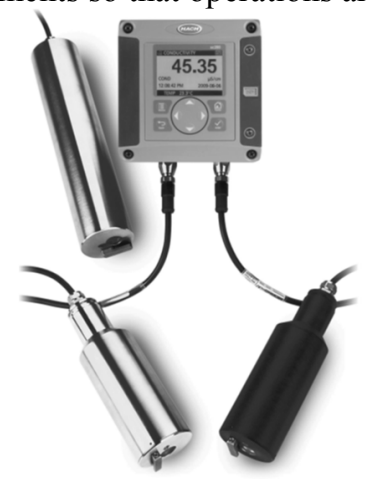

Figure 4. Solitax sc Suspended Solid Sensor

4. Sofrel Remote Logging Unit (RTU) / Logger

As a communication tool for sending data in locations to servers in the office. Also functions as the sender of data directly to the user if requesting via SMS.

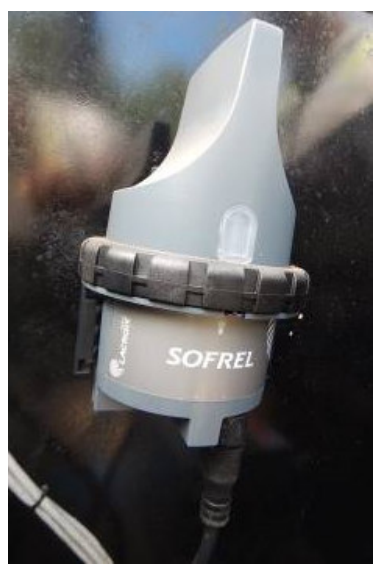

5. Electricity Source

Figure 5. Sofrel Remote Terminal Unit (RTU)

Resources that are used as electricity at the location of the system so that equipment can function consisting of solar panels, controllers and batteries.

6. Server and Application

Computers and servers are placed in offices using special applications so that incoming data can be stored and received properly and can be displayed on the Dashboard to make it easier for users to monitor the development of tools and changes in water quality. Shipping and receiving data using a GSM communication network.

All equipment is placed in a metal box and a wire fence is installed to maintain equipment security. Only sensors are released to come into direct contact with water at the point of compliance. 


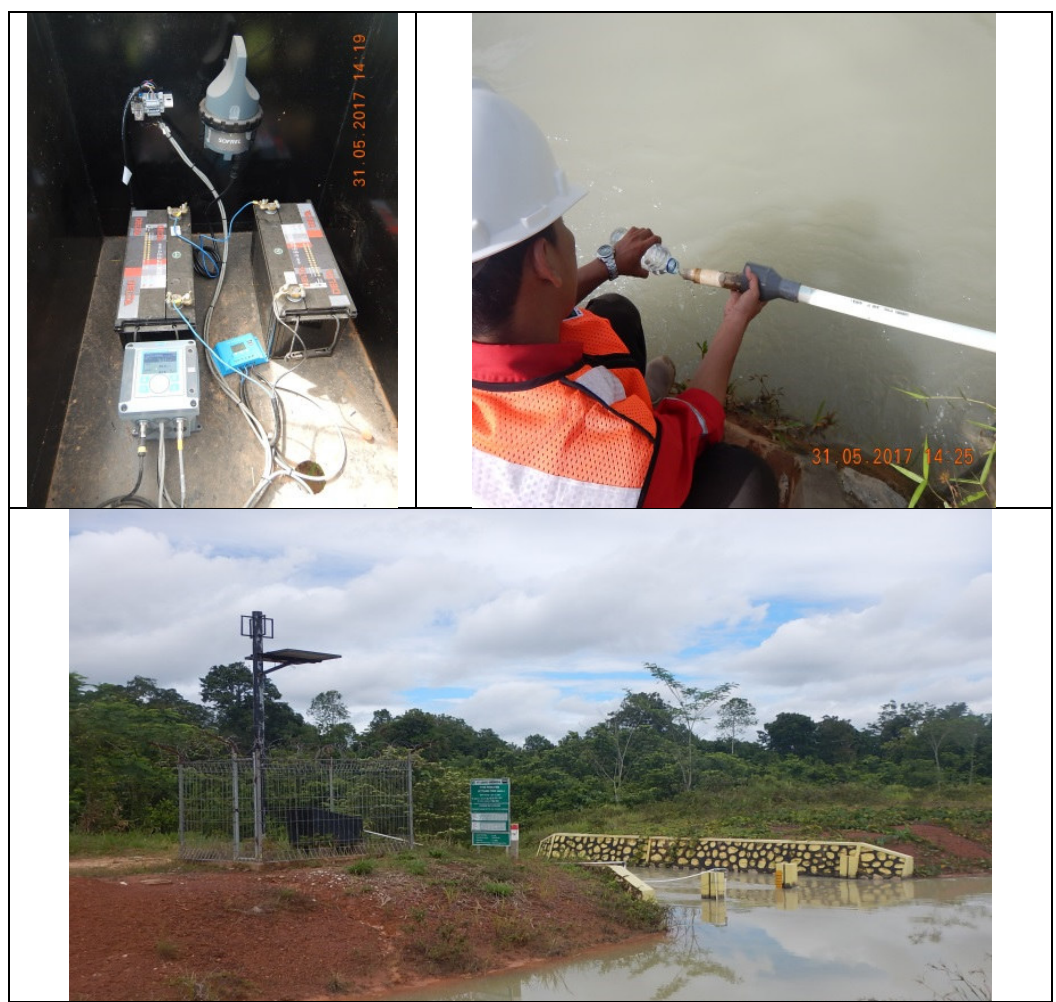

Figure 6. Position of equipment at the point of compliance

The results of monitoring water quality ( $\mathrm{pH}$ and TSS) can be well received after installation of equipment both at the compliance point and receiving equipment in the office. Data transmission to the server is carried out by loggers every 1 hour with the time of water sampling every 15 minutes.

Table 1. Results of monitoring $\mathrm{pH}$ and TSS quality of the SP N compliance point

\begin{tabular}{|c|c|c|}
\hline \multirow[t]{2}{*}{ Date } & SP O & SP O \\
\hline & pH Analyzer & TSS Analyzer \\
\hline 2017-05-30 08:00 PM & 6.75 & 56.80 \\
\hline 2017-05-30 08:15 PM & 6.75 & 58.26 \\
\hline 2017-05-30 08:30 PM & 6.75 & 56.80 \\
\hline 2017-05-30 08:45 PM & 6.73 & 53.89 \\
\hline 2017-05-30 09:00 PM & 6.75 & 50.98 \\
\hline 2017-05-30 09:15 PM & 6.75 & 56.80 \\
\hline 2017-05-30 09:30 PM & 6.75 & 53.89 \\
\hline 2017-05-30 09:45 PM & 6.75 & 58.26 \\
\hline 2017-05-30 10:00 PM & 6.75 & 53.89 \\
\hline 2017-05-30 10:15 PM & 6.75 & 56.80 \\
\hline 2017-05-30 10:30 PM & 6.75 & 61.17 \\
\hline 2017-05-30 10:45 PM & 6.73 & 56.80 \\
\hline 2017-05-30 11:00 PM & 6.72 & 58.26 \\
\hline 2017-05-30 11:15 PM & 6.72 & 58.26 \\
\hline 2017-05-30 11:30 PM & 6.72 & 58.26 \\
\hline 2017-05-30 11:45 PM & 6.69 & 67.00 \\
\hline 2017-05-31 12:00 AM & 6.72 & 64.09 \\
\hline 2017-05-31 12:15 AM & 6.72 & 65.54 \\
\hline 2017-05-31 12:30 AM & 6.69 & 61.17 \\
\hline 2017-05-31 12:45 AM & 6.69 & 64.09 \\
\hline
\end{tabular}




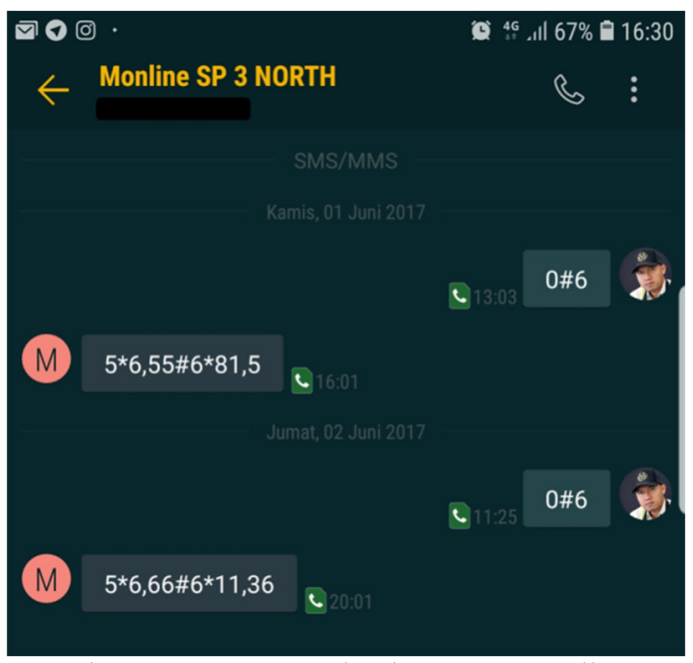

Figure 7. SMS monitoring water quality

On the dashboard or monitor server will show a graph / trend of water quality (pH and TSS). As well as other information regarding the health of the equipment installed, including if there is water quality that is close to the Environmental Quality Standard (BML). Early warning system in the form of an SMS notification if the sensor reads the water quality nearing the threshold of environmental quality standards will be sent to telephone numbers that have been registered in the system. This makes it very easy for the user to monitor the development of water quality at the compliance point so that before a water quality deviation occurs, it can immediately direct the team to take action to maintain water quality to always meet the required Environmental Quality Standards.

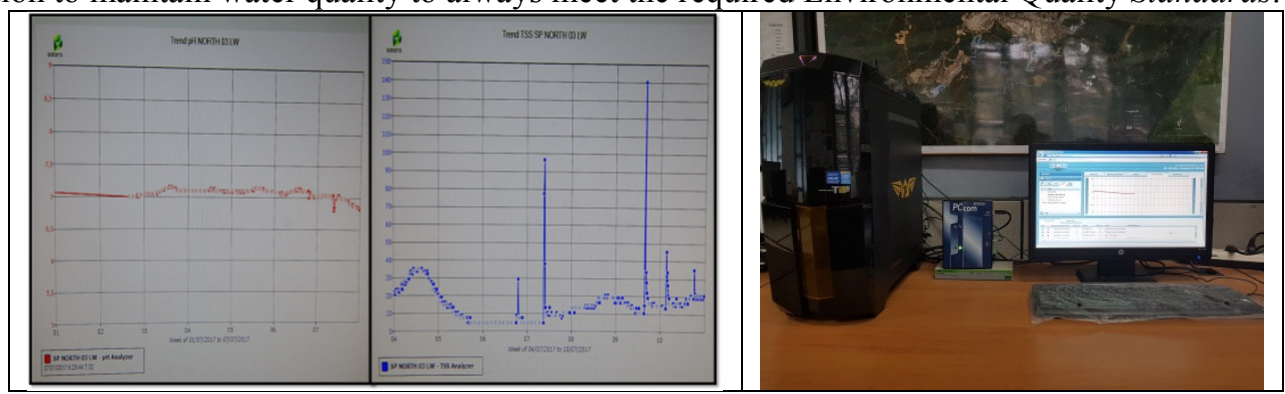

Figure 8. Water quality online monitoring dashboard

\section{Conclusions \& Recommendations}

In this study, an online water quality monitoring system (pH and TSS) has been designed and developed at one of Settling Pond's compliance points at PT. XY. The online monitoring system can do water sampling automatically every 15 minutes and send data to the server every 1 hour. Monitoring the results of water quality sampling can appear on the server Dashboard and can also remotely direct by the user to the logger to send updated water quality data. Development and changes in water quality can be monitored so that if a deviation occurs, action can be taken immediately to maintain water quality to always meet the required Environmental Quality Standards.

\section{References}

Ahmad Sabiq, Prabowo Nugroho Budisejati. 2017. pH, Temperature and Color Level Monitoring System in River Water Through a Web Based Wireless Sensor Network. Journal. Computer Technology and Systems.

Alaerts, G and Sumestri, S.S. 2004. Water Research Methods. Surabaya: National Business

Anonymous. 2014. Minister of Environment Decree Number 5 of 2014 concerning Waste Water Quality Standards. Jakarta: Environmental Secretariat.

Djabu, U. 2001. Guidelines for Field Study of Fecal Disposal and Wastewater in Educational Institutions, Sanitation and Environmental Health. Jakarta: Indonesian Ministry of Health's Pusdiknakes

Fitria, Y. 2008. Manufacture of liquid organic fertilizers from liquid waste in the fisheries industry using acetic acid and EM4 (effective microorganism 4). Bogor: Fisheries Product Technology Study Program, Faculty of Fisheries and Marine Sciences

Jose, C., Abdullah, C., Anggraini, Y., and Bahri, S. 2000. Nutrient enhancement of solid waste tapioca as a basic ingredient of animal feed by using effective microorganisms (EM). Semirata MIPA of West Region BKSPTN FMIPA University of Riau, Pekanbaru.

Kuswira, Febri.2012. Tofu Liquid Waste Processing With Aerob Bioreactor and Anaerobic Methods. ASE Journal. 
Mahida. 1986. Water Pollution and Utilization of Food Industry Waste. Jakarta: CV Rajawali.

Priyani Kusrini, Goib Wiranto, Iqbal Syamsu, Lilik Hasanah. 2016. Aquaculture Water Quality Online Monitoring System for Shrimp Farms Using Android-Based Applications. PPET - LIPI All right reserved order: 10.14203 / jet.v16.25-32.

Ridwan, Kemas.2012. Liquid Waste Treatment Know As An Environmentally Friendly Alternative Biogas Energy. ASE Journal

Siregar.2005. Waste Water Treatment Plant. Yogyakarta: Kanisius.

Suharto, Imam. 2002. Feasibility Study of Industrial Projects. Jakarta: Erlangga

Suharno and Asmadi. 2012. Basics of Waste Water Treatment Technology. Semarang: Gosyen Publishing.

Syamsi, Djohar. Utilization of Telemetry Technology for Monitoring and Control of River Water Pollution. INKOM, Vol. 6, No. 2, Article 192, Publication date: November 2012.

Yudi Yuliyus Maulana, Dadin Mahmudin, R. Indra Wijaya, Goib Wiranto. 2015. Integrated Water Quality Monitoring in Integrated Time. PPET - LIPI All rights reserved, Published: June 30, 2015, ISSN 1411-8289. 